\title{
Plural, coeducativo e gratuito: o primeiro ginásio/colégio público em Florianópolis (Santa Catarina, Brasil)
}

Plural, coeducative and free: the first public middle/high school in Florianópolis (Santa Catarina, Brazil)

Plural, coeducativo y gratuito: la primera escuela secundaria publica en Florianópolis (Santa Catarina, Brasil)

Juliana Topanotti dos Santos de Mello Universidade do Estado de Santa Catarina (Brasil)

https://orcid.org/0000-0002-9439-9774

http://lattes.cnpq.br/2286158161943536 julianatopanotti@uol.com.br

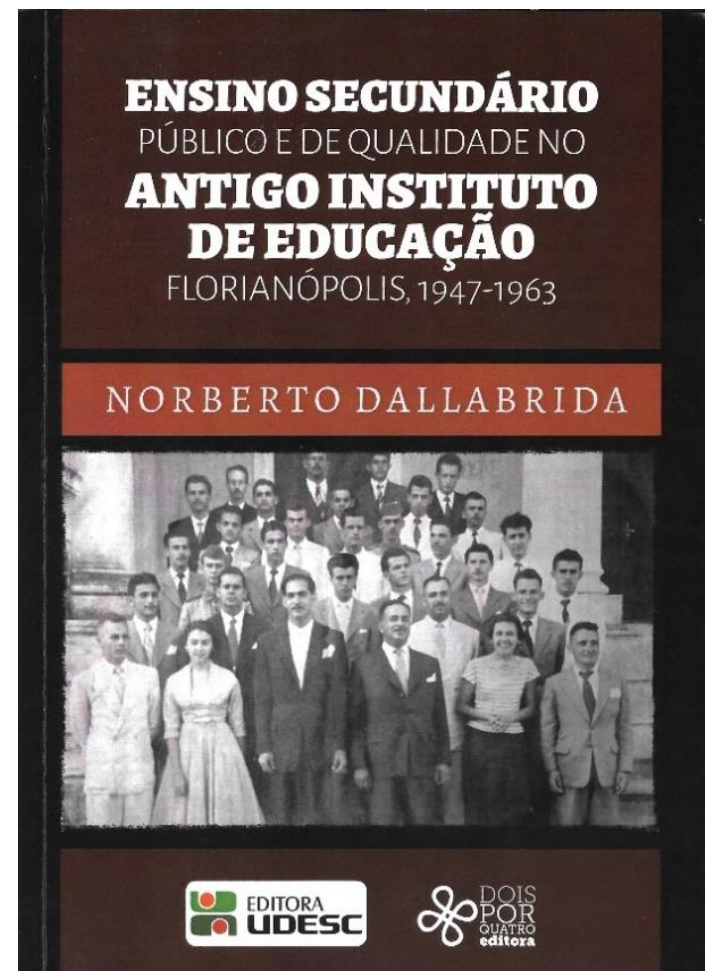

DALLABRIDA, Norberto. Ensino Secundário público e de qualidade no antigo Instituto de Educação: Florianópolis, 1947-1963. Florianópolis: Udesc; Dois por Quatro. 2017. 176p. 
O livro "Ensino Secundário Público e de Qualidade no antigo Instituto de Educação Florianópolis, 1947 - 1963”, publicado pelo pesquisador Norberto Dallabrida, em 2017 pela Editora Udesc e Dois Por Quatro Editora, traz uma importante contribuição para o campo da História da Educação catarinense. Esta obra, que destaca a história do primeiro estabelecimento público que ofertou o ensino secundário de forma gratuita no estado de Santa Catarina, traz à luz as práticas educacionais colocadas em marcha nesta instituição no período no qual ele funcionou no mesmo prédio que a Escola Normal Catarinense, qual seja de 1947 a 1963 . O destaque dado a este período justifica-se pela pouca atenção dada a estes primeiros anos, visto que em 1963 com a mudança para um novo prédio, o maior de Santa Catarina e o significativo aumento no número de estudantes e professores/as, há um apagamento da história inicial desta instituição. O livro é composto de uma apresentação que situa o/a leitor/a acerca do processo de constituição de um ginásio e posteriormente de um colégio neste espaço educacional; dois ensaios: um sobre a cultura escolar e o outro focalizando o corpo docente e três entrevistas realizadas pelo autor com dois professores e uma professora que atuaram nesta escola no período recortado para este estudo.

No estado de Santa Catarina, no início da década de 1940, não havia escola secundária pública e na capital catarinense havia apenas dois estabelecimentos escolares que ofertavam esse ramo de ensino. Ambos colégios eram confessionais católicos e estavam divididos por gênero: O Colégio Catarinense destinado aos rapazes e o Colégio Coração de Jesus que atendia às moças. Neste panorama, no qual o ensino secundário era possível apenas para os/as estudantes que tivessem famílias com condições econômicas de arcar com as mensalidades escolares ou aqueles/as poucos/as que, geralmente articulando o seu capital social junto aos políticos catarinenses, conseguiam uma bolsa de estudos, a abertura de uma escola pública, gratuita e coeducativa significou expandir a possiblidade de acesso a este nível de ensino para os/as adolescentes catarinenses. Desta forma, em 1947, teve início o curso ginasial no Ginásio Dias Velho e três anos mais tarde duas turmas de curso colegial (uma de curso clássico e outra de curso científico) foram abertas no período noturno.

O primeiro ensaio trata da cultura escolar engendrada nesta instituição escolar no período recortado para o estudo. O autor não só buscou indícios de como a Lei Orgânica do Ensino Secundário (BRASIL, 1942), ou seja, a cultura escolar prescrita, foi apropriada pelo corpo dirigente e docente no cotidiano escolar, mas também cotejou com a cultura escolar dos outros dois colégios que ofereciam o ensino secundário em Florianópolis: Colégio Catarinense e Colégio Coração de Jesus. Além de ser público e gratuito, o Colégio Dias Velho diferenciavase dos outros dois estabelecimentos por ser laico, coeducativo, oferecer o segundo ciclo no 
período noturno, estas características impactavam a clientela atendida. Outra característica que distinguia esta instituição escolar era que o ingresso dos professores era realizado por meio de concurso público e desta forma, o corpo docente era diversificado. Estas e outras questões permitiam que a cultura escolar fosse constituída de forma irredutível em relação às outras duas escolas. Por exemplo, o enquadramento discente era menos regulador no Colégio Dias Velho do que nas outras duas instituições, apesar de também existir.

No segundo ensaio é traçado um perfil dos professores e professoras que atuaram no colégio no período de 1947 a 1963. Dallabrida analisa este perfil partindo da formação escolar, preferências culturais, políticas e religiosas do conjunto de docentes que atuavam no estabelecimento de ensino neste início da história da instituição. Tratando da formação a reflexão recai sobre as possibilidades de formação para estes(as) professoras(as) que à época eram muito restritas, haviam poucas faculdades e universidades em todo território nacional. Este cenário na capital catarinense era ainda mais acanhado. A Faculdade de Filosofia, Ciências e Letras que seria a responsável em garantir a formação adequada para estes/as professores/as só passou a funcionar em Florianópolis em 1955. Todas estas dificuldades ficam visíveis quando se observa o quadro de formação do corpo docente, poucos e poucas haviam se formado no curso superior que o/a habilitava para a docência no ensino secundário. E em alguns casos os/as professoras/as tinham somente o diploma do Curso Normal e do Curso Primário. Em relação às preferências culturais, políticas e religiosas o corpo docente era bem diversificado: havia liberais, comunistas, católicos, espíritas, filiados a diferentes partidos políticos e com variadas visões de mundo. $\mathrm{O}$ autor ressalta o clima de respeito entre todos os/as professores e na pesquisa não foi encontrada nenhuma situação que configurasse censura ou mesmo conflito. Havia pluralidade de pensamentos e de formas de apropriarem-se do currículo prescrito.

As três entrevistas configuram um material riquíssimo, que em parte já foi descrito e analisado nos dois ensaios também presentes no livro, mas que também podem servir de fontes de pesquisa para outros estudos. Eglê Malheiros, que lecionou História; Celestino Sachet, professor de Língua Francesa e Osvaldo Ferreira de Mello docente da disciplina de Língua Portuguesa discorrem sobre suas trajetórias acadêmicas e na docência, bem como sobre suas atividades como professores/ a e sobre a atmosfera da escola. Relembram situações vividas no trabalho com os estudantes secundaristas e refletem sobre a posição deste colégio dentro da configuração escolar da capital catarinense. Dentro destas trajetórias, os entrevistados e a entrevistada também relatam as particularidades de suas carreiras profissionais. A professora Eglê Malheiros conta sobre o seu abrupto afastamento das atividades docentes em razão da ditadura civil-militar. A constituição da Universidade Federal de Santa Catarina e da 
Universidade do Estado de Santa Catarina foram determinantes nos caminhos dos outros dois professores, que passaram a lecionar no ensino superior, deixando as atividades na escola secundária. Por estas três entrevistas é possível entrever como o grupo de professores/as atuantes na instituição era diverso e algo que os três entrevistados relatam que é havia um clima de profundo respeito pelas posições de quaisquer professores ou professoras. Além disso ressaltam como esse clima de diversidade era revertido em um enriquecimento do cotidiano escolar, pois os/as estudantes podiam conviver com a docência destes professores e professoras tão diversos.

Num momento da história educacional brasileira na qual o Ensino Médio, que ainda não foi totalmente universalizado e democratizado, passa por uma nova reforma institucional é fundamental revisitar experiencias de escolarização pública e gratuita que tinham prestígio junto à comunidade escolar e que conseguiam atingir os objetivos a que se propunham. Ressaltar o clima de diversidade cultural e política, a presença da coeducação, a escola laica, onde, mesmo com alguma rigidez disciplinar, havia a abertura para a participação dos/as estudantes é necessário. Ilumina a reflexão sobre o Ensino Médio atual e auxilia a compreender o que é essencial nesta etapa de ensino.

\section{Referência}

BRASIL. Decreto-lei n. 9.092, de 12 de março de 1946. Cria um ginásio de aplicação nas Faculdades de Filosofia do país. Diário Oficial da União. Rio de Janeiro, 12 mar. 1946. Disponível em: http://www2.camara.leg.br/legin/fed/declei/1940-1949/decreto-lei-9053-12marco-1946-417016-publicacaooriginal-1-pe.html. Acesso em: 14 jun. 2017. 